\title{
QPSK MODULATOR FOR X-BAND IRS SATELLITES
}

\author{
Sumitha Deepak ${ }^{1}$, Apoorva Hegde ${ }^{2}$ \\ ${ }^{1}$ Assistant Professor, Department of ECE, T. John Institute of Technology, Bangalore, Karnataka, India \\ ${ }^{2}$ Assistant Professor, Department of ECE, T. John Institute of Technology, Bangalore, Karnataka, India
}

\begin{abstract}
The current work is applied to remote sensing satellites. IRS satellites in the orbits are not only sending data to Indian ground stations but also to other international stations for passing data to different countries. Multiple solid-state cameras are carried by the IRS satellite to operate in the visible and infrared bands that acquires imageries for earth survey such as agriculture and geology. Digital phase modulation that allows transmitting discrete phase angles is more popular and easily adaptable. Among the PSK schemes, the QPSK is adopted as it is relatively easy to realize and gives optimum performance in terms of power and bandwidth compared to other modulation schemes. The unit is realized in MIC form, which is smaller in size and weight compared to earlier ones. The data obtained from onboard camera is transmitted to ground on X-band carrier (8-8.4GHz). Keeping in view the future satellite applications, a QPSK modulator is designed with LVDS interface circuit for a data rate of upto 105 Mbps. The microwave simulation software used is EESOF.
\end{abstract}

Keywords: Hybrid Coupler, Wilkinson Power Combiner, Thin Film Technology.

\section{INTRODUCTION}

This work emphasizes the simulation and testing of a QPSK modulator for Indian Remotes Sensing satellites with the intention of having a data rate upto 105Mbps. The entire modulator is housed in MIC form using microstrip techniques. The operating frequency range is X-band (8$8.4 \mathrm{GHz}$ ). For optimum performance simulation and test results are done for a band of $600 \mathrm{MHz}$ range.

QPSK modulator in the parallel configuration consists of a quadrature power divider, two BPSK modulators and an inphase power combiner. Parallel configuration is preferred because of good amplitude and phase imbalance. Here carrier signal is divided by an in-phase, 3-dB hybrid coupler and applied to two identical BPSK modulators on both arms. The output of BPSK modulators is combined in a power combiner to produce the desired QPSK signal.

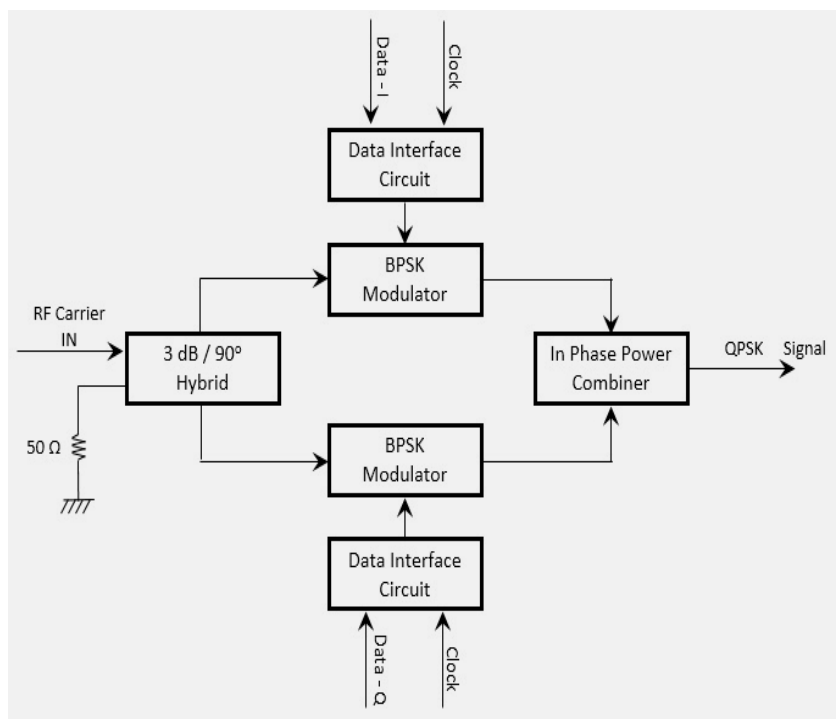

Fig-1: Parallel configuration of QPSK Modulator

\subsection{Hybrid Coupler}

A $3 \mathrm{~dB}, 90^{\circ}$ hybrid coupler [4] is a four-port device that splits an input signal equally with a resultant $90^{\circ}$ phase shift between output ports or combines two signals while maintaining high resolution between the ports.

A signal applied to port 1 gets equally split between ports 2 and 3 with one of the outputs exhibiting a relative $90^{\circ}$ phase shift. Almost all the signal applied to port 1 is transmitted to loads connected to ports 2 and 3 that are properly terminated into matching impedances. Port 4 is termed "isolated 'and receives negligible power.

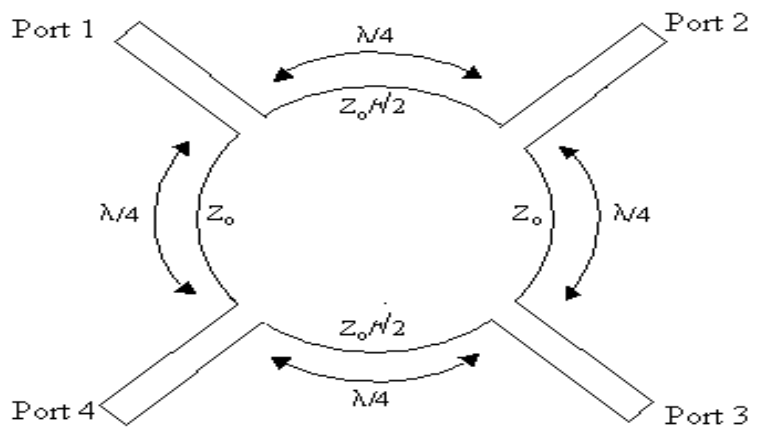

Fig-2: $90^{\circ}$ Hybrid

Table-1: 3dB Hybrid phase Truth table

\begin{tabular}{|c|c|c|c|c|}
\hline & Port 1 & Port 2 & Port 3 & Port 4 \\
\hline Port 1 & - & Isolated & $\begin{array}{r}-3 \mathrm{~dB} \\
-90^{\circ}\end{array}$ & $0^{-3 \mathrm{~dB}}$ \\
\hline Port 2 & Isolated & - & $0^{-3 \mathrm{~dB}}$ & $\begin{aligned} & -3 \mathrm{~dB} \\
- & 90^{\circ}\end{aligned}$ \\
\hline Port 3 & $\begin{aligned} & -3 \mathrm{~dB} \\
- & 90^{\circ}\end{aligned}$ & $\begin{array}{c}-3 \mathrm{~dB} \\
0^{\circ}\end{array}$ & - & Isolated \\
\hline Port 4 & $\begin{array}{l}-3 \mathrm{~dB} \\
0^{\circ}\end{array}$ & $\begin{aligned} &-3 \mathrm{~dB} \\
&-90^{\circ}\end{aligned}$ & Isolated & - \\
\hline
\end{tabular}




\subsection{Wilkinson Power Combiner}

Wilkinson power combiner combines the two bi-phase modulated signals. The output port isolation is achieved through a resistor. When divider splits a signal or combines coherent signals, each side of the isolation resistor is at equal potential and therefore no current flows through the resistor and no power is dissipated.

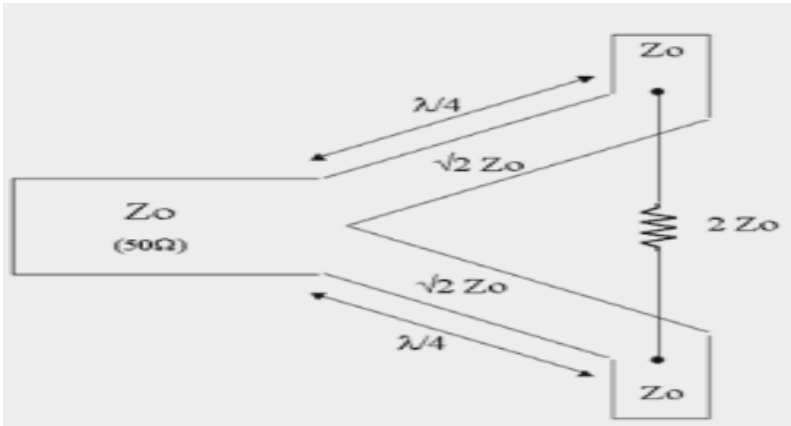

Fig-3: Uncompensated Wilkinson Power combiner

The simple Wilkinson power combiner [2] supports limited bandwidth applications. Since bandwidth required is more for current application, a broad band combiner is designed. The simulation results show that there is improvement in bandwidth by choosing compensated Wilkinson power combiner. The performance is improved by adding a $\lambda / 4$ transformer in front of the power division step and a shift in the impedance levels.

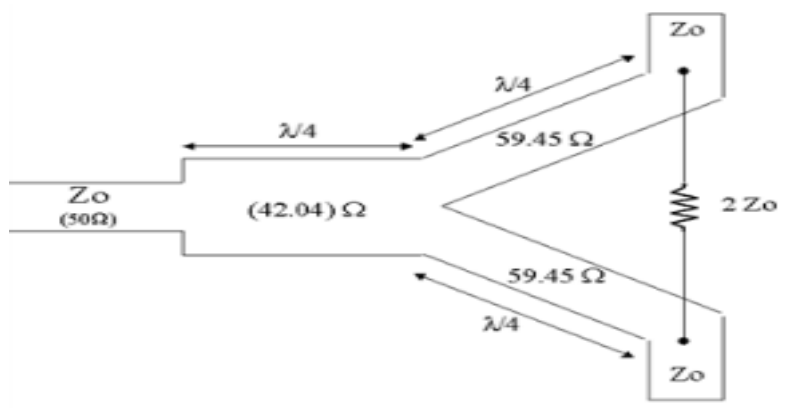

Fig-4: Compensated Wilkinson Power combiner

The output VSWR in uncompensated circuit is better than in compensated circuit, while input VSWR in compensated circuit is better. Therefore, the choice may be dictated by input/output characteristic as well as whether necessary space exists to add the extra quarter wave transformer.

\section{DESIGN AND FABRICATION}

MIC modulates two data streams provided by the base band system on X-Band carrier. The MIC is fabricated on Alumina substrate using microstrip line techniques and thin film technology. The two bi-phase modulators are hybrid reflection type and use a pair of high-speed PIN diodes (HPND 4050) as switching elements.

\subsection{Choice of substrate}

Dielectric constant is generally the first parameter to look for when choosing a microwave substrate material. It governs whether the circuit will fit in the allotted space or not and operate in its required frequency range. The material suitable for our application was found to be alumina with $\varepsilon_{\mathrm{r}}$ 9.8. It is made of polycrystalline $\mathrm{Al} 2 \mathrm{O} 3$ with small amounts of metal oxide glasses to achieve certain physical properties. Alumina is available in sizes ranging from 0.01 " to $0.05^{\prime \prime}$ or greater and variety of shapes and design.

\subsection{Design Equations}

\section{Hybrid coupler:}

For Alumina Substrate $\varepsilon_{\mathrm{r}}=9.8, \mathrm{~h}=0.625 \mathrm{~mm}, \mathrm{t}=.005 \mathrm{~mm}$. At $\mathrm{X}$-Band, $\mathrm{f}=8.2 \mathrm{GHz}$

Width of the transmission line [2]:

$\mathrm{W} / \mathrm{h}=8 \mathrm{e}^{\mathrm{A}} /\left(\mathrm{e}^{2 \mathrm{~A}}-2\right)$ where

$\mathrm{A}=\left(\mathrm{Z}_{\mathrm{o}} / 60\right) \sqrt{ }\left(\varepsilon_{\mathrm{r}}+1\right) / 2+\left(\varepsilon_{\mathrm{r}}-1 / \varepsilon_{\mathrm{r}}+1\right)\left(0.23+0.11 / \varepsilon_{\mathrm{r}}\right.$ For $50 \Omega$,

$\mathrm{W} / \mathrm{h}=0.975 \Rightarrow \mathrm{W}=0.61 \mathrm{~mm}$

For $\mathrm{Z}_{\mathrm{o}} / \sqrt{ } 2=35.35 \Omega$,

$\mathrm{W}=1.17 \mathrm{~mm}$

\section{$\lambda$ / 4 length:}

For $50 \Omega, \lambda=\lambda_{\mathrm{o}} / \sqrt{ } \varepsilon_{\text {eff }}=\mathrm{c} / \mathrm{f} \sqrt{ } \varepsilon_{\text {eff }}$

Since $\mathrm{W} / \mathrm{h} \leq 1$,

$\varepsilon_{\text {eff }}=\left(\varepsilon_{\mathrm{r}}+1\right) / 2+\left(\varepsilon_{\mathrm{r}}-1\right) / 2\left[(1+12 \mathrm{~h} / \mathrm{W})^{-1 / 2}+0.04(1-\mathrm{W}\right.$ $\left./ \mathrm{h})^{2}\right]$

So, $\varepsilon_{\text {eff }}=6.6$

$\lambda=14.24 \mathrm{~mm}, \lambda / 4=3.56 \mathrm{~mm}$

For $35.35 \Omega$, since $\mathrm{W} / \mathrm{h} \geq 1$,

$\varepsilon_{\text {eff }}=\left(\varepsilon_{\mathrm{r}}+1\right) / 2+\left(\varepsilon_{\mathrm{r}}-1\right) / 2(1+12 \mathrm{~h} / \mathrm{W})^{-1 / 2}$

So, $\lambda / 4=3.45 \mathrm{~mm}$

Ring radius:

$\lambda / 4=2 \pi \mathrm{r} / 4=3.56 \mathrm{~mm}$

$\mathrm{r}=2.26 \mathrm{~mm}$ (for $50 \Omega)$

$=2.19 \mathrm{~mm}($ for $35.35 \Omega)$

Power combiner:

$\mathrm{W} / \mathrm{h}=8 \mathrm{e}^{\mathrm{A}} /\left(\mathrm{e}^{2 \mathrm{~A}}-2\right)$ where

$\mathrm{A}=\left(\mathrm{Z}_{\mathrm{o}} / 60\right) \sqrt{ }\left(\varepsilon_{\mathrm{r}}+1\right) / 2+\left(\varepsilon_{\mathrm{r}}-1 / \varepsilon_{\mathrm{r}}+1\right)\left(0.23+0.11 / \varepsilon_{\mathrm{r}}\right)$

$\varepsilon_{\mathrm{eff}}=\left(\varepsilon_{\mathrm{r}}+1\right) / 2+\left(\varepsilon_{\mathrm{r}}-1\right) / 2(1+12 \mathrm{~h} / \mathrm{W})^{-1 / 2}$

$\lambda=\lambda_{\mathrm{o}} / \sqrt{\varepsilon_{\mathrm{eff}}}=\mathrm{c} / \mathrm{f} \sqrt{ } \varepsilon_{\mathrm{eff}}$

$\lambda / 4=2 \pi \mathrm{r} / 4$

Table-2: Design values for power combiner

\begin{tabular}{|l|l|l|l|l|}
\hline $\mathbf{Z}(\mathbf{\Omega})$ & $\mathbf{W}(\mathbf{m m})$ & $\boldsymbol{\varepsilon}_{\text {eff }}$ & $\lambda / \mathbf{4}(\mathbf{m m})$ & $\mathbf{r}(\mathbf{m m})$ \\
\hline 70.7 & 0.27 & 6.27 & 3.65 & 2.32 \\
\hline 42.04 & 0.85 & 6.8 & 3.5 & - \\
\hline 59.45 & 0.41 & 6.42 & 3.6 & 2.29 \\
\hline
\end{tabular}

\subsection{Schematic And Simulation}

The design of hybrid coupler and power combiner is fabricated on the alumina substrate using thin film technology. The schematics obtained using the simulation tool is given in fig-5and fig-6. 


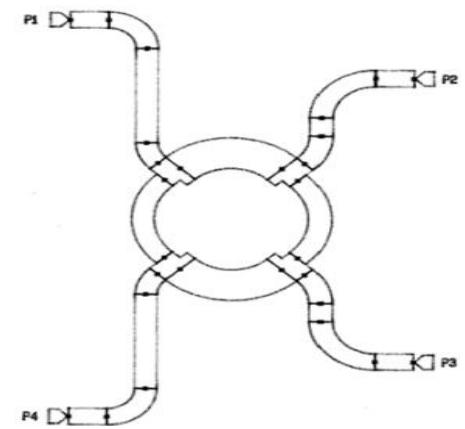

Fig-5: Schematic of hybrid coupler

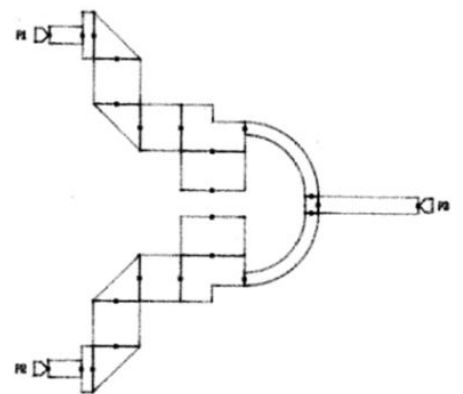

Fig-6: Schematic of power combiner

\section{SIMULATION AND TEST RESULTS}

\subsection{Test Set-Up For QPSK Modulator}

Modulator is basically tested for two conditions: static and dynamic. In dynamic condition the carrier suppression with $1010 \ldots .$. data and spectrum with random data is observed.

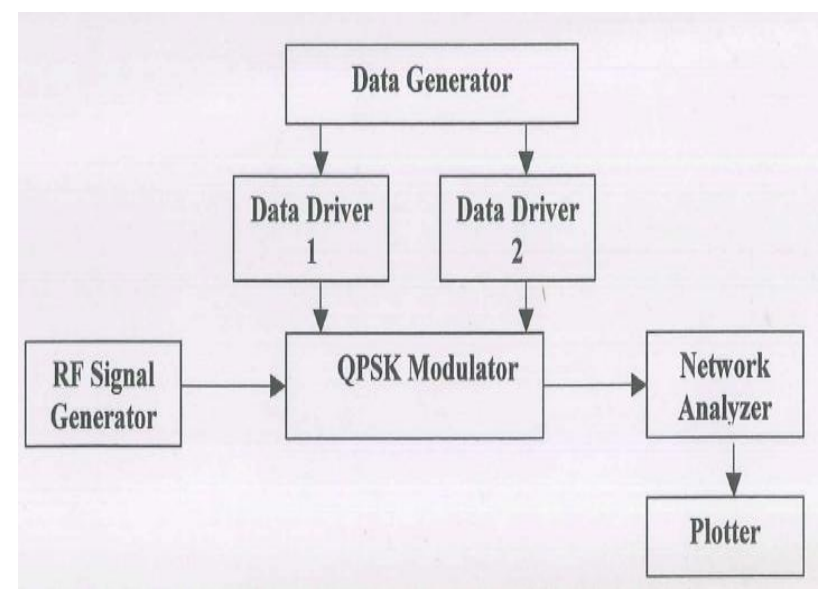

Fig-7: Test set-up

The base band systems and RF systems are placed in different deck plates in the spacecraft. Because of this, the coaxial cables between the two systems will be around 4 meters in length. The disturbed parasitic reactance of the cables deteriorates the rise time and fall time of the data. To solve this problem, an interface circuit using Low Voltage Differential Signaling (LVDS) chips are incorporated to forward/ reverse bias the PIN diodes of the modulator. The TTL levels are converted to bipolar levels using transistors.

This work replaces the TTL circuit which has a frequency limitation. With LVDS, higher data rates can be achieved.

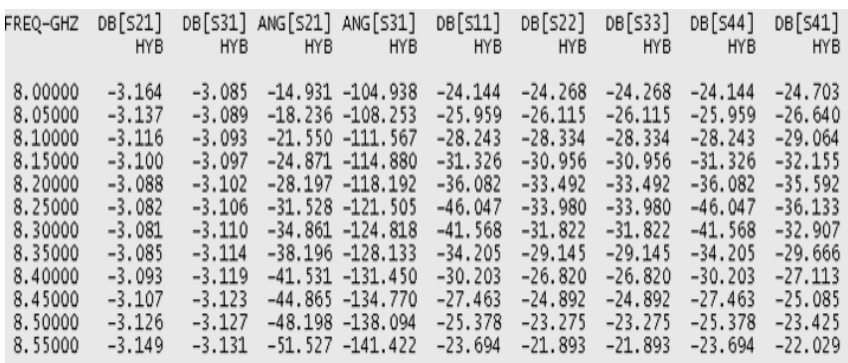

Fig-8: Simulation results for hybrid coupler (snapshot from EESOF)

\begin{tabular}{|c|c|c|c|c|c|c|c|c|c|}
\hline$\underset{\mathrm{Greq}}{\text { Freq }}$ & $\begin{array}{c}\text { db } \\
{[\text { S221] }}\end{array}$ & $\begin{array}{c}\mathbf{d b} \\
{[\mathbf{S} 31]}\end{array}$ & $\begin{array}{l}\text { Ang } \\
\text { S21 }\end{array}$ & $\begin{array}{l}\text { Ang } \\
\text { S31 }\end{array}$ & $\begin{array}{c}\text { db } \\
{[\mathrm{S} 41]}\end{array}$ & $\begin{array}{c}\text { db } \\
\text { [S11] }\end{array}$ & $\begin{array}{c}\mathbf{d b} \\
\text { [S22] }\end{array}$ & $\begin{array}{c}\text { db } \\
\text { [S33] }\end{array}$ & $\begin{array}{c}\text { db } \\
{[\mathrm{S} 44}\end{array}$ \\
\hline 8.0 & -3.47 & -3.9 & 80.9 & 172.6 & -20.1 & -15.6 & -18.1 & -14.9 & -24.2 \\
\hline 8.05 & -3.56 & -4.00 & 73.5 & 164.6 & -22.0 & -16.9 & -19.4 & -16.5 & -20.6 \\
\hline 8.1 & $-3,42$ & -4.00 & 66.8 & 157.3 & -24.6 & -14.2 & -19.8 & -16.8 & -20.0 \\
\hline 8.15 & -3.42 & -3.98 & 58.5 & 151.7 & -22.3 & -13.5 & -22.7 & -17.1 & -21.6 \\
\hline 8.2 & -3.65 & -3.90 & 51.2 & 144.1 & -21.6 & -16.7 & -19.3 & -14.6 & .23 .3 \\
\hline 8.25 & -3.83 & -3.88 & 45.6 & 139.4 & -20.1 & -18.1 & -16.4 & -15.5 & -23.4 \\
\hline 8.3 & -3.74 & -3.92 & 38.8 & 131.7 & -26.1 & -17.5 & -17.8 & -15.2 & -25.8 \\
\hline 8.35 & -3.85 & -3.87 & 31.8 & 124.2 & -27.5 & -23.7 & -16.4 & -15.2 & -31.9 \\
\hline 8.4 & -3.84 & -3.80 & 25.6 & 117.8 & -30.2 & -32.5 & -11.0 & -14.4 & .20 .9 \\
\hline 8.45 & -3.77 & -3.68 & 20.3 & 111.1 & -32.8 & -21.6 & -10.6 & -15.3 & -17.8 \\
\hline 8.5 & -3.70 & -3.88 & 13.4 & 102.3 & -24.9 & -18.0 & -13.6 & -17.8 & -21.6 \\
\hline 8.55 & -3.61 & -3.78 & 6.2 & 95.9 & -23.5 & -19.8 & -17.3 & .21 .0 & .23 .8 \\
\hline 8.6 & -3.56 & -3.67 & 0.4 & 88.9 & -19.7 & -16.8 & -22.2 & -31.4 & -18.4 \\
\hline
\end{tabular}

Fig-9: Hardware test results for hybrid coupler

\begin{tabular}{|c|c|c|c|c|c|c|c|}
\hline FREQ-GHZ & $\begin{array}{r}\mathrm{DB}[531] \\
\mathrm{CC}\end{array}$ & $\begin{array}{r}\mathrm{DB}[532] \\
\mathrm{CC}\end{array}$ & ANG $[531]$ & $\begin{array}{r}\text { ANG [532] } \\
\mathrm{CC}\end{array}$ & $\mathrm{DB}[511]$ & $\begin{array}{r}\mathrm{DB}[522] \\
\mathrm{CC}\end{array}$ & $\begin{array}{r}\mathrm{DB}[533] \\
\mathrm{CC}\end{array}$ \\
\hline $\begin{array}{l}8.00000 \\
8.05000 \\
8.10000 \\
8.15000 \\
8.20000 \\
8.25000 \\
8.30000 \\
8.35000 \\
8.40000 \\
8.45000 \\
8.50000 \\
8.55000\end{array}$ & $\begin{array}{l}-3.065 \\
-3.067 \\
-3.069 \\
-3.071 \\
-3.073 \\
-3.076 \\
-3.078 \\
-3.080 \\
-3.083 \\
-3.085 \\
-3.086 \\
-3.088\end{array}$ & $\begin{array}{l}-3.065 \\
-3.067 \\
-3.069 \\
-3.071 \\
-3.073 \\
-3.076 \\
-3.078 \\
-3.080 \\
-3.083 \\
-3.085 \\
-3.086 \\
-3.088\end{array}$ & $\begin{array}{r}18.476 \\
15.903 \\
13.330 \\
10.756 \\
8.182 \\
5.607 \\
3.029 \\
0.448 \\
-2.136 \\
-4.724 \\
-7.317 \\
-9.917\end{array}$ & $\begin{array}{r}18.476 \\
15.903 \\
13.330 \\
10.756 \\
8.182 \\
5.607 \\
3.029 \\
0.448 \\
-2.136 \\
-4.724 \\
-7.317 \\
-9.917\end{array}$ & $\begin{array}{l}-23.264 \\
-24.484 \\
-25.867 \\
-27.437 \\
-29.184 \\
-30.975 \\
-32.334 \\
-32.474 \\
-31.266 \\
-29.461 \\
-27.632 \\
-25.968\end{array}$ & $\begin{array}{l}-23.264 \\
-24.484 \\
-25.867 \\
-27.437 \\
-29.184 \\
-30.975 \\
-32.334 \\
-32.474 \\
-31.266 \\
-29.461 \\
-27.632 \\
-25.968\end{array}$ & $\begin{array}{l}-33.073 \\
-30.704 \\
-28.967 \\
-27.627 \\
-26.561 \\
-25.697 \\
-24.992 \\
-24.412 \\
-23.936 \\
-23.549 \\
-23.236 \\
-22.987\end{array}$ \\
\hline
\end{tabular}

Fig-10: Simulation results for power combiner (snapshot from EESOF)

\begin{tabular}{|l|l|l|c|c|c|c|c}
\hline Freq & $\begin{array}{c}\mathbf{d b} \\
{[\mathbf{S 3 1}]}\end{array}$ & $\begin{array}{c}\mathbf{d b} \\
{[\mathbf{S 3 2}]}\end{array}$ & $\begin{array}{c}\mathbf{A n g} \\
\mathbf{S 2 1}\end{array}$ & $\begin{array}{c}\mathbf{A n g} \\
\mathbf{S 3 1}\end{array}$ & $\begin{array}{c}\mathbf{d b} \\
{[\mathbf{S 1 1}]}\end{array}$ & $\begin{array}{c}\mathbf{d b} \\
{[\mathbf{S 2 2}]}\end{array}$ & $\begin{array}{c}\mathbf{d b} \\
{[\mathbf{S 3 3}]}\end{array}$ \\
\hline 8.0 & -3.8 & -4.01 & -107.86 & -108.37 & -18.9 & -25.5 & -14.6 \\
\hline 8.05 & -3.8 & -4.0 & -113.09 & -113.54 & -18.0 & -24.4 & -12.3 \\
\hline 8.1 & -3.8 & -3.9 & -119.74 & -120.66 & -19.1 & -26.6 & -13.5 \\
\hline 8.15 & -3.8 & -3.9 & -125.63 & -126.76 & -17.5 & -22.6 & -16.5 \\
\hline 8.2 & -3.8 & -3.9 & -129.85 & -130.31 & -13.7 & -16.5 & -15.6 \\
\hline 8.25 & -3.9 & -4.0 & -137.36 & -138.43 & -13.1 & -15.9 & -13.4 \\
\hline 8.3 & -3.9 & -3.9 & -142.33 & -143.31 & -15.2 & -19.5 & -14.6 \\
\hline 8.35 & -3.9 & -3.9 & -148.68 & -149.95 & -16.6 & -21.9 & -13.4 \\
\hline 8.4 & -4.0 & -4.1 & -153.82 & -154.75 & -14.7 & -19.8 & -10.0 \\
\hline 8.45 & -4.4 & -4.37 & -159.46 & -160.63 & -14.8 & -19.7 & -9.71 \\
\hline 8.5 & -4.3 & -4.2 & -165.88 & -167.56 & -19.8 & -36.0 & -11.3 \\
\hline 8.55 & -4.2 & -4.1 & -170.59 & -171.56 & -22.4 & -35.2 & -11.6 \\
\hline 8.6 & -4.28 & -4.12 & -175.32 & -176.41 & -22.1 & -30.7 & -13.9 \\
\hline
\end{tabular}

Fig-11: Hardware test results for power combiner

Fig- 8 shows that simulation results are tuned to a frequency around $8.2 \mathrm{GHz}$ to $8.4 \mathrm{GHz}$. Though overall hardware results are comparable to the simulation results it is approximately tuned between $8.2 \mathrm{GHz}$ to $8.35 \mathrm{GHz}$. Theoretically the insertion loss between the port 2 and port 3 of the hybrid coupler should be $3 \mathrm{~dB}$. From simulation the difference between the ports is $0.02 \mathrm{~dB}$ around the desired frequency range. There is $0.25 \mathrm{~dB}$ difference in hardware results around the same frequency range. The maximum phase imbalance is around $\pm 2^{\circ}$. The return loss is also equally good around the desired frequency varying between $15 \mathrm{~dB}$ to $25 \mathrm{~dB}$. 
The difference in the hardware results in the both the designs are due to the microstrip loss, connector loss, and junction discontinuities. The units have been tested on test fixtures where perfect grounding is not possible which is very important for microstrip lines.

\subsection{Layout And Test Results Of QPSK Modulator}

Fig-12 shows the layout of the QPSK modulator for fabrication on the substrate. The blank spaces in rectangular shape are the space isolators to be placed at the input and output ports.

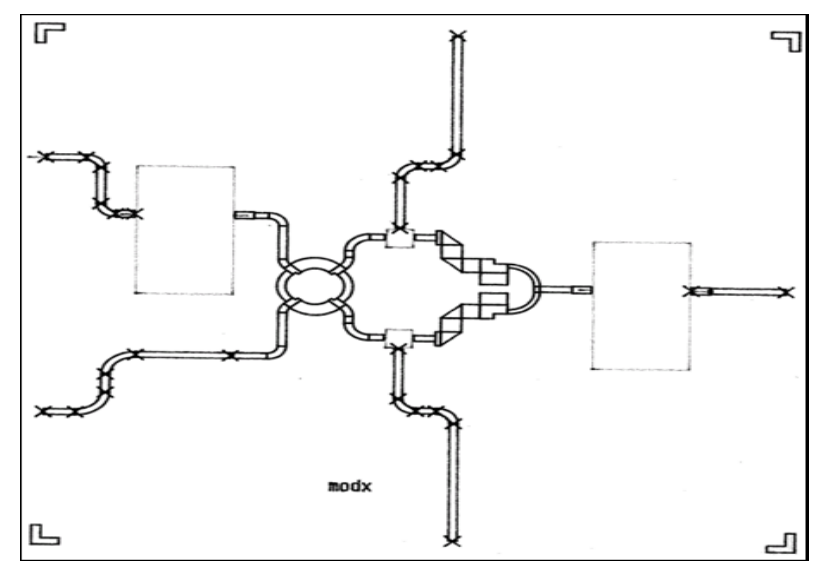

Fig-12: Layout of QPSK modulator

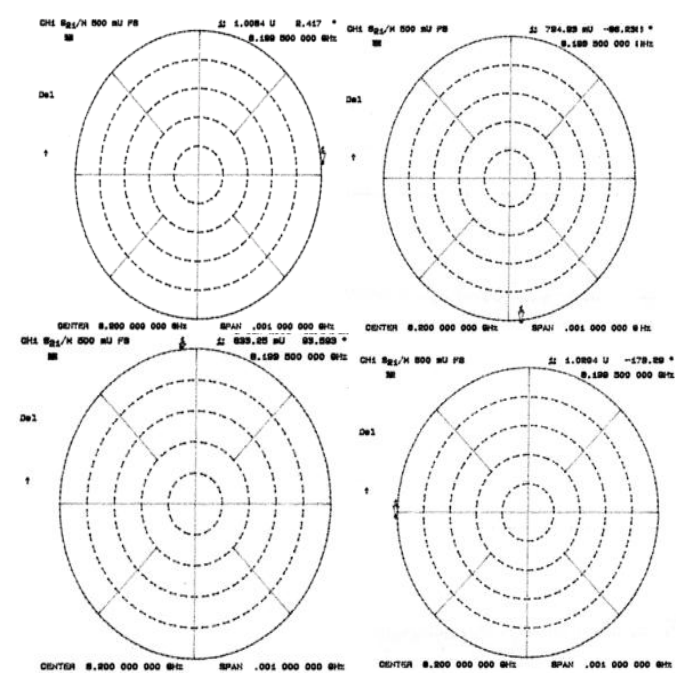

Fig-13: Phase plots of QPSK

Table-3: Phases of four states in the desired frequency band (Hardware test results)

\begin{tabular}{|l|l|l|l|l|}
\hline \multirow{2}{*}{$\begin{array}{l}\text { Freq } \\
(\text { GHz })\end{array}$} & \multicolumn{4}{|l}{ Phase in degrees } \\
\cline { 2 - 5 } & $\mathbf{0 0}$ & $\mathbf{0 1}$ & $\mathbf{1 0}$ & $\mathbf{1 1}$ \\
\hline 8 & 0 & -86.5 & 90 & 179.8 \\
\hline 8.1 & -1.2 & -89.2 & 87.3 & 176.9 \\
\hline 8.2 & 1 & -86.2 & 93.5 & 179.3 \\
\hline 8.3 & 0 & -94 & 94 & 177.8 \\
\hline 8.4 & 1.4 & -88.7 & 91.3 & 178.2 \\
\hline
\end{tabular}

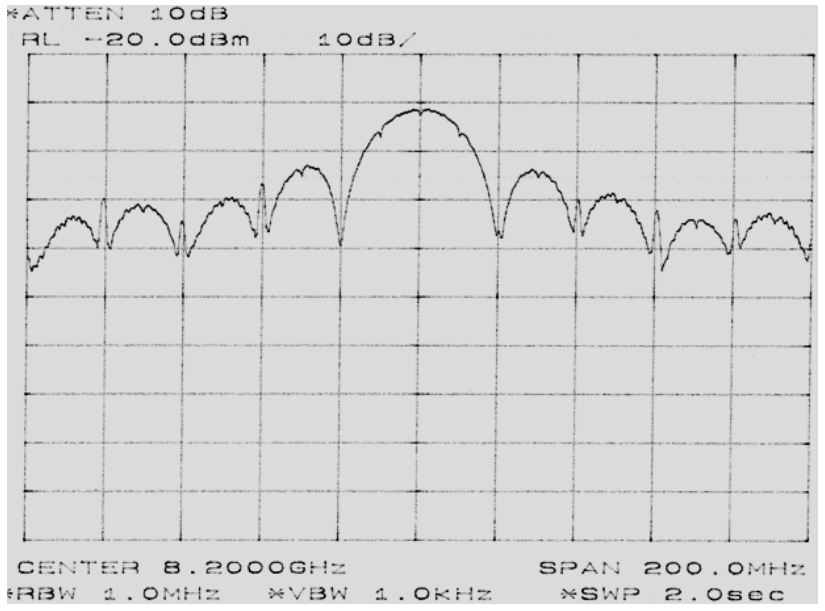

Fig-14: QPSK spectrum (from spectrum analyzer)

The dc content in the random data results in the spikes in the QPSK spectrum.

\section{CONCLUSION AND FUTURE WORK}

The modulator is designed using microstrip lines on Alumina substrate with thin film technology, for a center frequency of $8.2 \mathrm{GHz}$. The simulation and test results are compared and seen to match to a large extent.

Since the bandwidth is limited at X-band, higher modulation schemes are to be explored in the future scope. As an extension of this work 8-PSK design has been taken up to converse the bandwidth at the cost of power requirements. With proper housing the modulator will be tested for environmental conditions like temperature, vibration, hot and cold tests etc. then the bandwidth achieved is not at the desired frequency. The frequency shift can be corrected by redesigning to a higher frequency so that frequency dispersion is taken care of.

\section{REFERENCES}

[1]. Juergen Butz, Walter Gross, Bernd Hespeler, Volker Lahr, and M. Spinnler. "High Data Rate Direct X-Band QPSK Modulator", 22nd AIAA International Communications Satellite Systems Conference \& Exhibit 2004 (ICSSC), International Communications Satellite Systems Conferences (ICSSC)

[2]. Byrareddy, C. R.; Reddy, N. C. Easwar; Sridhar, C. S. "Design of hybrid \& power combiner at X-band for UQPSK using microstriplines", Space Science and Communication (IconSpace), 2011 IEEE International Conference on, On page(s): 296 - 301

[3]. Maria Siddiqua, Design \& Analysis of an X-Band QPSK Modulator using Direct Carrier Modulation Technique, Multitopic Conference, INMIC 2006,

[4]. R.E Collin- Foundations for microwave Engineering, (IEEE Press series on Electromagnetic Wave Theory), John Wiley \& Sons, 2004

[5]. Halen Howe - Strip line Circuit Design Dr. J.J Bahl \& D.K Trivedi- A Designer's Guide to Microstrip line.

[6]. National's LVDS Manual 
[7]. Simon Haykin, Introduction to Analog \& Digital Communication, 1989, John Wiley \& Sons, Inc. Canada.

\section{BIOGRAPHIES}

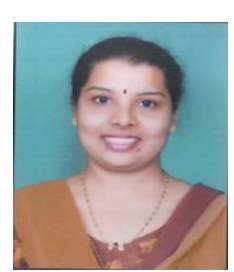

Sumitha Deepak, post graduated from RV College of Engineering, Bangalore, has 8 years of teaching experience in NITK, Surathkal, Karnataka, Dayanand Sagar College of Engineering, Bangalore and PESIT, Bangalore. She is currently serving as an Asst. Professor at T.John Institute of Technology, Bangalore. Her areas of research interests include Digital Communication and Antenna Design.

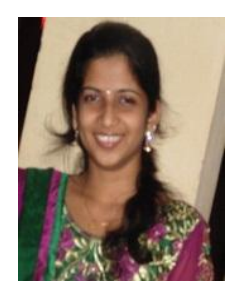

Apoorva Hegde, received her B.E degree from P.A College of Engineering, Mangalore, and her M.Tech degree from NMAMIT Nitte Karkala .She has served as an Assistant Professor in Canara Engineering College, Mangalore and is currently working as Assistant Professor in the Electronics and communication department at T.John Institute of Technology, Bangalore. 